\title{
HIỆU QUẢ IN VITRO PHỐI HỢP COLISTIN VỚI MINOCYCLINE VÀ COLISTIN VỚI DOXYCYCLINE TRÊN VI KHUẨN ACINETOBACTER BAUMANNII ĐA KHÁNG
}

\author{
Dương Hữu Phước ${ }^{1}$, Trương Thiên Phú ${ }^{2}$ Lê Văn Chương,4, \\ Ngô Quốc Đạt ${ }^{4}$, Huỳnh Minh Tuấn ${ }^{4,5}$
}

\section{TÓM TẮT}

Đăt vấn đề: Hiên nay $A$. baumannii đang nổi lên như một nguyên nhần hàng đâu gây ra nhiểm khuẩn bênh viện và tỷ lệ đề kháng kháng sinh ngày càng gia tăng. Colistin hiện nay được xem là lựa chọn điều trị cuối cùng nhưng có nhiều tác dụng phu trển thận và thần kinh. Do đó liệu pháp phối hợp kháng sinh được khuyến cáo sử dung trên lâm sàng giúp giảm tác dụng phụ của colistin và MIC của kháng sinh phối hợp, gia tăng khả năng diệt khuẩn. Mục tiêu: Đánh giá hiệu quả in-vitro trong kháng sinh đồ phối hợp giữa colistin với minocycline và colistin với doxycycline trên vi khuẩn $A$. baumannii đa kháng. Phương pháp nghiên cứu: 96 chủng vi khuẩn $A$. baumannii đa kháng phân lập từ Bệnh viện Đại học Y Dược Tp HCM từ 12/202106/2021. Thực hiệ̉n kháng sinh đồ phối hợp giữa colistin với minocycline và colistin với doxycycline theo phương pháp vi pha loãng (Checkerboard) trên bảng nhưa 96 giếng và xác định chỉ số FIC để đánh giá hiêu quả phối hợp kháng sinh. Kết quả: Colistin còn hiệu quả in vitro trên $A$. baumannii đa kháng với tỷ lệ kháng là $4.2 \%$ và $\mathrm{MIC} 90=2 \mathrm{mg} / \mathrm{L}$. Phối hợp colistin với minocycline và colistin với doxycycline làm gia tăng hiệu quả cho nhau (hiệp đồng hoặc cộng) với tỷ lệ lần lượt là $94.8 \%$ và $96.9 \%$. Khi phối hợp nồng độ colistin $\leq 2 \mathrm{mg} / \mathrm{L}$ làm giảm MIC của minocycline và doxycycline có ý nghĩa từ kháng sang nhay hoăc trung gian với tỷ lệ lần lượt là $96.4 \%$ và $35.5 \%$. Kểt luận: A. baumannii đa kháng có mức kháng thấp với colistin in vitro. Sự phối hợp colistin với minocycline và colistin với doxycycline làm gia tăng hiệu quả in vitro cho nhau với tỷ lệ cao trên $A$. baumannii đa kháng.

Tư khóa: Acinetobacter baumannii, phối hợp kháng sinh, colistin, minocycline, doxycycline.

\section{SUMMARY}

\section{IN-VITRO EFFICACY OF ANTIBIOTIC} COMBINATION BETWEEN COLISTIN WITH MINOCYCLINE/DOXYCYCLINE AGAINST MULTIDRUG RESISTANT ACINETOBACTER BAUMANNII

\footnotetext{
${ }^{1}$ Bệnh viện đa khoa tỉnh Gia Lai

${ }^{2}$ Bệnh viện Chỡ Rẫy

${ }^{3}$ Trung tâm Kiểm chuân Chất lượng Xét nghiệm Y học, Đại học Y Dược Tp Hồ Chí Minh

${ }^{4}$ Đại họ Y Dược Tp Hồ Chí Minh

${ }^{5}$ Bềnh viên Đai hoc Y Dướ Tp Hồ Chí Minh

Chịu trách nhiệm chính: Huỳnh Minh Tuấn

Email: huynhtuan@ump.edu.vn

Ngày nhận bài: 12.8.2021

Ngày phản biên khoa họ: 7.10.2021

Ngày duyệt bài: 18.10 .2021
}

Background: Currently Multi-drug resistant (MDR) $A$. baumannii is one of leading causes of nosocomial infections and antimicrobial resistant incidence is increasing. Colistin is currently assumed as a last resort for treatment, however it causes many nephrotoxic and neurotoxic effects. Therefore, antibiotic combination therapy is recommended for clinical use to help reduce colistin toxicity and MIC of the combination antibiotic, increasing the ability to eradicate bacteria. Objective: To evaluate the in vitro efficacy of antibiotic combination between colistin with minocycline and colistin with doxycycline against MDR A. baumannii. Research method: 96 strains of MDR A. baumannii were collected from the University Medical Center - Ho Chi Minh City from 01/2021$06 / 2021$. Then, antibiotic combination test colistin with minocycline and colistin with doxycycline was performed by the checkerboard microdilution method and determined the FICI index to evaluate effectiveness of the antibiotic combination. Results: Colistin was still effective in vitro against MDR A. baumannii with resistance rate of $4.2 \%$ and MIC90 $=$ $2 \mathrm{mg} / \mathrm{L}$. The combination of colistin with minocycline and colistin with doxycycline increased the effectiveness of each other (synergistically or additively) by $94.8 \%$ and $96.9 \%$ respectively. The combination of colistin concentrations $\leq 2 \mathrm{mg} / \mathrm{L}$ significantly reduced the MIC from resistant to sensitive or intermediate of minocycline (96.4\%) and doxycycline (35.5\%). Conclusion: colistin is still in vitro effecticacy against MDR $A$. baumannii. The combination of colistin with minocycline and colistin with doxycycline increases the mutual effect at a high rate on MDR A. baumannii.

Keywords: Acinetobacter baumannii, antibiotic combination, colistin, minocycline, doxycycline.

\section{I. ĐĂT VẤN ĐỀ}

Hiện nay $A$. baumannii là một trong những căn nguyên gây nhiễm khuẩn bệnh viện thường gặp nhất. Theo báo cáo tại hội nghị khoa học toàn quốc về Hồi sức Cấp cứu và Chống độc năm 2017 thì tỷ lệ kháng của $A$. baumannii trên 90\% đối với các kháng sinh thế hệ mới tại các tỉnh phía Nam Việt Nam [1]. Đặc biệt Multi-drug resistant (MDR) A. baumannii đang nổi lên như một nguyên nhân gây ra nhiêu đợt bùng phát toàn câuu và tỷ lê ngày càng tăng gây khó khăn trong việc lựa chọn kháng sinh trong điều trị nhiễm khuẩn do MDR A. baumannii.

Colistin hiện nay là lựa chọn điều trị cuối cùng đối với những vi khuẩn đa kháng như $A$. 
baumannii vì tỷ lệ đề kháng thấp. Tuy nhiên colistin lại gây ra nhiêu tác dụng phụ cho thận và thần kinh .Vì vậy việc tối ưu hóa liều dùng colistin trong điều trị là điều rất cần thiết. Ớ những bệnh nhân nặng như bệnh nhân suy đa cơ quan, bệnh nhân suy giảm chức năng thận thì những bệnh nhân này là bắt buộc [4].

Do đó phối hợp kháng sinh hiện nay là liệu pháp thường xuyên được khuyến cáo sử dụng trên lâm sàng để tối ưu hóa liều lượng của colistin và giảm MIC của kháng sinh phối hợp với colistin, gia tăng khả năng diệt khuẩn, hạn chế kháng thuốc. Chính vì vậy chúng tôi tiến hành nghiên cứu: "Hiệu quả in vitro trong phối hợp kháng sinh colistin với minocycline và colistin với doxycycline trên vi khuẩn $A$. baumannii đa kháng".

\section{II. ĐỐI TƯợNG VÀ PHƯƠ'NG PHÁP NGHIÊN CỨU}

2.1 Đối tượng nghiên cứu. 96 chủng vi khuẩn MDR A. baumannii trong tổng số 160 chủng $A$. baumannii được phân lập từ Bệnh viện Đại học Y Dược Tp HCM từ 12/2021 06/2021. Các chủng này được phân lập từ các bệnh phẩm của các khoa lâm sàng khác nhau, được định danh trên hệ thống máy Phoenix ${ }^{T M}$ M50 (Becton Dickinson-Mỹ) và thực hiện kháng sinh đồ bằng phương pháp Kirby-Bauer theo tiêu chuẩn Viện tiêu chuẩn xét nghiệm lâm sàng $\mathrm{Hoa}$ Kỳ (CLSI 2021).

\subsection{Phương pháp nghiên cứu}

Thực hiện xác định MIC của colistin, minocycline, doxycycline trên 96 chủng MDR A. baumannii. Sau đó thực hiện kháng sinh đồ phối hợp giữa colistin-minocycline và colistindoxycycline theo phương pháp vi pha loãng (Checkerboard) trên bảng nhựa 96 giếng và xác định chỉ số FIC với.

$$
\begin{aligned}
& \text { FIC (A) }=\text { MIC (A khi có B) } / \text { MIC (chí A) } \\
& \text { FIC }(B)=\operatorname{MIC}(B \text { khi có A) } / \text { MIC (chỉ B) } \\
& \mathrm{FIC} \text { index }=\mathrm{FIC}(\mathrm{A})+\mathrm{FIC}_{(\mathrm{B})}
\end{aligned}
$$

\begin{tabular}{|c|c|c|c|c|}
\hline & $\begin{array}{c}\text { Hiệp } \\
\text { đồng }\end{array}$ & Cộng & $\begin{array}{c}\text { Độc } \\
\text { lập }\end{array}$ & $\begin{array}{c}\text { Đối } \\
\text { kháng }\end{array}$ \\
\hline $\begin{array}{c}\text { FIC } \\
\text { index }\end{array}$ & $\leq 0.5$ & $0.5-1$ & $=1-4$ & $\geq 4$ \\
\hline
\end{tabular}

Dựa trên chỉ số FIC index để đánh giá hiệu quả phối hợp kháng sinh là hiệp đồng, cộng, độc lập và đối kháng [5]. Kiểm soát chẩt lượng kháng sinh theo CLSI 2021 và hóa chất theo tiêu chuẩn nhà sản xuất.

Hóa chất: colistin, minocycline, doxycycline (Sigma Aldrich-Singapore). Dung dịch muller hinton broth (Merck-Đức).

\section{KẾT QUẢ NGHIÊN CỨU}

Từ 12/2021-06/2021, Bệnh viện Đại học Y
Dược Tp HCM đã phân lập 160 chủng A. baumannii.

\subsection{Tỉ lệ đề kháng kháng sinh}

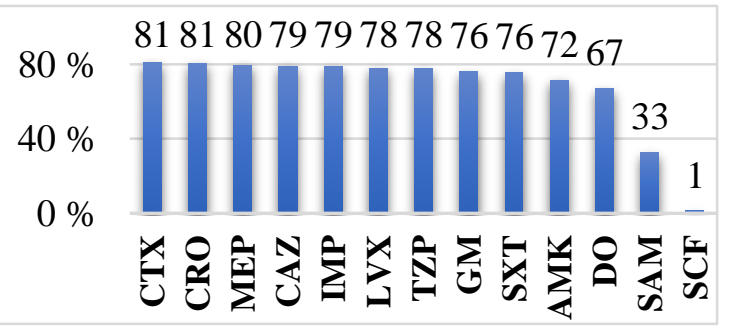

(SCF: cefoperazone/sulbactam; SAM: ampicilline/sulbactam; Do: doxycycline; AMK: amikcin; SXT: trimethoprim/sulfamethoxazole; GM: gentamicin; TZP: piperacillin/tazobactam; LVX: levofloxacin; IMP: imipenem; CAZ: ceftazidime; MEP: meropenem; CRO ceftriaxone; CTX: cefotaxime)

Biểu đồ 3.1 Tì lệ đề kháng kháng sinh của $A$. baumannii $(n=170)$

Nhân xét: cefoperazone/sulbactam và ampicilline/sulbactam có tỷ lệ đề kháng thấp trên A. baumannii. Các kháng sinh khác có tỷ lệ kháng ở mức cao từ $67 \%$ đến $81 \%$.

3.2 Phân bố $A$. baumannii trong bệnh phẩm và các khoa lâm sàng. Trong tổng số 160 chủng $A$. baumannii cho thấy đàm chiếm tỷ lệ rất cao $(53.6 \%)$, còn lại là mủ $(8.9 \%)$, máu (6.5\%), nước tiểu (5.4\%), dịch các loại $(23.2 \%)$ và ít nhất là dịch não tủy $(0.6 \%)$. ớ các khoa lâm sàng thì khoa Hồi sức tích cực chiếm tỷ lệ cao nhất $(35.5 \%)$, còn lại chiếm tỷ lệ thấp từ $1.8-7.7 \%$.

3.3 Tỷ lệ phân lập A baumannii so với vi khuẩn khác. $A$. baumannii chiếm tỷ lệ $5.1 \%$ trong tổng số vi khuẩn phân lập được, đứng thứ 5 sau E. coli $(24.4 \%)$, Klebsiella sp. $(24.1 \%)$, Staphylococcus sp. (16.3\%) và Pseudomonas sp. (6.4\%).

3.4 Tỷ lệ MIC của colistin (Co), minocycline (Mi), doxycycline (Do).

Bảng 3.1 Tý lệ MIC Co, Do và Mi (mg/L)

\begin{tabular}{|l|c|c|c|c|c|}
\hline & R & S & I & MIC90 & MIC50 \\
\hline Mi & $87.4 \%$ & $6.3 \%$ & $6.3 \%$ & 32 & 16 \\
\hline Do & $96.9 \%$ & $3.1 \%$ & $0 \%$ & 256 & 256 \\
\hline Co & $4.2 \%$ & $0 \%$ & $95.8 \%$ & 2 & 1 \\
\hline
\end{tabular}

Nhânn xét: MDR A. baumannii có tỷ lệ kháng thấp với $\mathrm{Co}(4.2 \%)$. Mi, Do có tỷ lệ kháng cao và MIC50 và MIC90 của Mi thấp hơn so với Do.

3.5 Hiệu quả phối hợp kháng sinh đồ in vitro colistin với minocycline và colistin với doxycycline trên vi khuẩn MDR $A$. baumannii.

Bảng 3.2 Hiệu quả phôi hợp colistin với 
minocycline và colistin với doxycycline

\begin{tabular}{|c|c|c|c|c|}
\hline $\begin{array}{c}\text { Kháng } \\
\text { sinh }\end{array}$ & $\begin{array}{c}\text { Hiệp } \\
\text { đồng }\end{array}$ & Cộng & $\begin{array}{c}\text { Độc } \\
\text { lập }\end{array}$ & $\begin{array}{c}\text { Đối } \\
\text { kháng }\end{array}$ \\
\hline Co-Mi & $58.3 \%$ & $36.5 \%$ & $5.2 \%$ & $0 \%$ \\
\hline Co-Do & $59.3 \%$ & $37.6 \%$ & $3.1 \%$ & $0 \%$ \\
\hline
\end{tabular}

Nhận xét: Phối hợp colistin với minocycline và colistin với doxycycline làm gia tăng hiệu quả cho nhau (hiệp đồng hoặc cộng) với tỷ lệ cao lần lượt là $94.8 \%$ và $96.9 \%$. Không có trường hợp nào đối kháng.

3.5.1 Giảm MIC của colistin khi có mặt minocycline. Phối hợp Co với Mi trên 96 chủng MDR A. baumannii chúng tôi thấy MIC của Co khi có mặt của Mi giảm rõ rệt so với MIC của Co đơn thuần.

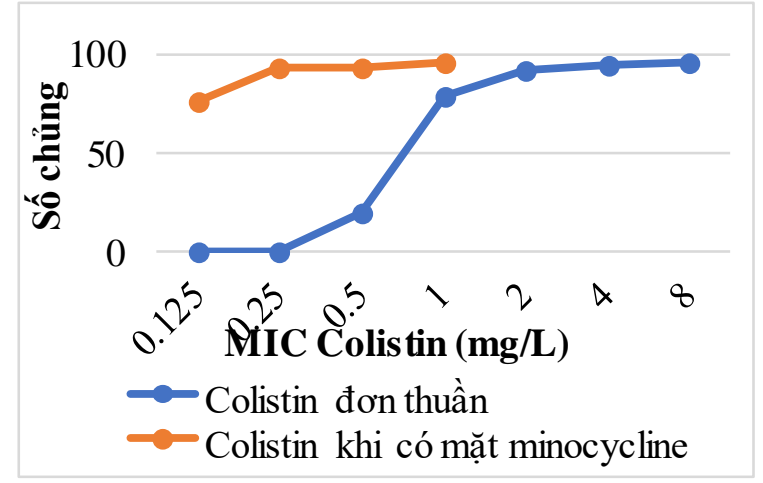

Biểu đồ 3.2 Biểu đồ tích lũy giảm MIC của colistin khi có măt minocycline

Nhận xét: Đường biểu diễn Co khi có mặt Mi (màu cam) dịch chuyển sang bên trái so với đường biểu diển Co đơn thuần (màu xanh), nghĩa là giá trị MIC của Co giảm rõ rệt khi có mặt Mi

3.5.2 Giảm MIC của colistin khi có mặt doxycycline. Phối hợp Co với Mi trên 96 chủng MDR A. baumannii chúng tôi thây MIC của Co khi có mặt của Do giảm rõ rệt so với MIC của Co đơn thuần.

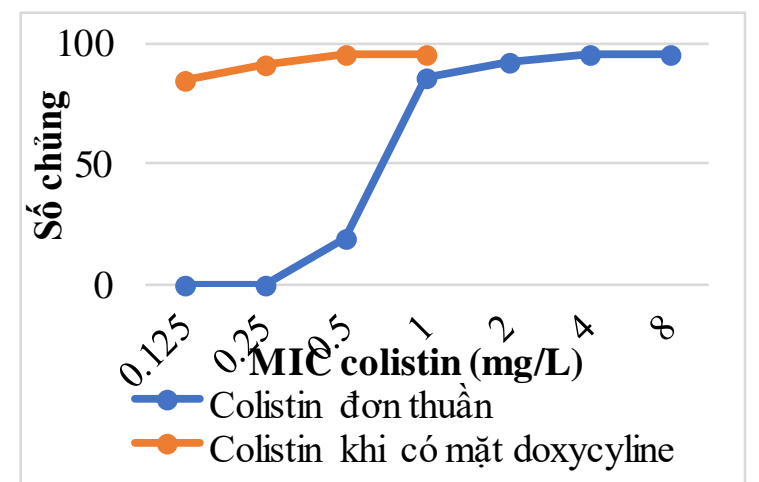

Biêu đồ 3.3 Biểu đồ tích lũy giảm MIC của colistin khi có mặt docycline
Nhận xét: Tương tự với biểu đồ 3.2 trên ta cũng thấy giá trị MIC của Co giảm rõ rệt khi có mặt Do.

\subsubsection{Giảm MIC có ý nghĩa của Mi (Do)} khi có mặt Co.

Bảng 3.2 Giảm MIC có ý nghĩa của Mi, Do khi có mặt Co $\leq 2 \mathrm{mg} / \mathrm{L}$

\begin{tabular}{|c|c|}
\hline & R chuyến thành I, S \\
\hline Mi khi có mă̆t Co & $96.4 \%$ \\
\hline Do Khi có mặt Co & $35.5 \%$ \\
\hline
\end{tabular}

Nhân xét: Theo CLSI 2021, MIC Mi (Do) < 8 $\mathrm{mg} / \mathrm{L}$ là nhạy, $=8 \mathrm{mg} / \mathrm{L}$ là trung gian và $>8$ $\mathrm{mg} / \mathrm{L}$ là kháng [7]. Theo bảng trên ta thấy sự có mặt của $\mathrm{Co} \leq 2 \mathrm{mg} / \mathrm{L}$ làm giảm MIC của $\mathrm{Mi}$ từ $\mathrm{R}$ chuyển thành I, S (tức MIC $>8 \mathrm{mg} / \mathrm{L}$ sang MIC $\leq 8 \mathrm{mg} / \mathrm{L}$ ) với tỷ lệ rất cao $96.4 \%$. Còn với Do thì sự có mặt của Co $\leq 2 \mathrm{mg} / \mathrm{L}$ làm giảm MIC của Do từ $\mathrm{R}$ chuyển thành $\mathrm{I}, \mathrm{S}$ thấp hơn (35.5\%).

\section{BÀN LUÂN}

Với kết quả mục 3.1 cho thấy $A$. baumannii phân bố trên bênh phẩm đàm và khoa Hồi sức tích cực với tỷ lệ cao gấp nhiều lần so với các bệnh phẩm và khoa lâm sàng khác. Điều này cho thấy đặc tính của $A$. baumannii chủ yếu gây bệnh đường hô hấp có liên quan đến viêm phổi thở máy và viêm phổi Bệnh viện. Tuy nhiên thì tỷ lệ phân lập $\mathrm{A}$. baumannii (5.1\%) trong tổng số vi khuẩn tại Bệnh viện Đại học Y Dược Tp Hồ Chí Minh so với các Bệnh viện khác trong khu vực thấp hơn như Bệnh viện Phạm Ngọc Thạch 19.1\% (2017), Quẩn Y 175 là 29.8\% (2018)...

Tình hình đề kháng kháng sinh của $A$. baumannii tại Bệnh viện Đại học Y Dược Tp Hồ Chí Minh cũng ở mức khá cao. Biểu đồ 3.1 cho thấy các kháng sinh hay sử dụng trên lâm sàng đều ở mức trên $70 \%$. Riêng với cefoperazone/ sulbactam, ampicilline/sulbactam có tỷ lệ kháng thấp trên $A$. baumannii. Nếu so với các Bệnh viện khác trong khu vực thì tỷ lệ kháng cefoperazone/sulbactam, ampicilline/sulbactam lại ở mức khá thấp. Như Bệnh viện Quân Y 175 với tỷ lệ lần lượt là $100 \%$ và $100 \%$, Bệnh viện Kiên Giang (2019) lần lượt là $66.2 \%, 71.4 \%$. Còn với colistin cũng cho thấy tỷ lệ kháng thấp so với thế giới từ 2010-2019, tỷ lệ chung của $A$. baumannii kháng polymyxin trung bình là $13 \%$ trong đó Châu Mỹ 29\%, Châu Âu 13\% và Châu Á 10\% [2].

Thực hiện kháng sinh đồ phối hợp colistinminocycline và colistin-doxycycline làm gia tăng hiệu quả cho nhau (hiệp đồng hoặc cộng) lần lượt là $94.8 \%$ và $96.9 \%$ trên 96 chủng MDR A. baumannii trong nghiên cứu (bảng 3.2). Với tỷ lệ trên cho thây 2 kháng sinh gia tăng hiệu quả in 
vitro cho nhau ở mức rất cao. Dựa trên biểu đồ 3.2 và 3.3 , ta cũng có thể thây được MIC colistin giảm xuống rõ rệt khi phối hợp với Mi (Do). Nếu xét nồng độ $\leq 8 \mathrm{mg} / \mathrm{L}$, kết quả nghiên cứu cho thấy làm giảm MIC của Co thì Mi làm giảm nhiều hơn so với Do và nồng độ này có ý nghĩa lâm sàng. Vậy với kết quả trên ta có thể tham khảo in vitro để phối hợp Co với Mi và Co với Do để giảm nồng độ của Co xuống, giảm tác dụng phụ trên bệnh nhân cũng như hạn chế kháng thuốc.

So sánh với nghiên cứu khác cũng cho kết quả cao như tác giả Yang YS, et al. khi phối hợp Co với Mi làm gia tăng hiệu quả cho nhau (hiệp đồng hoặc cộng) là 92\% [6]. Tương tự với Co với Do là $70 \%$ của tác giả Miyasaki $Y$, et al. [3].

Bên cạnh đó bảng 3.2 cũng cho ta thấy sự mặt của Co $\leq 2 \mathrm{mg} / \mathrm{L}$ cũng giảm MIC của Mi từ $\mathrm{R}$ chuyển thành I, S với tỷ lệ cao $96.4 \%$. Còn với Do là $35.5 \%$. Ta thây MIC50 và MIC90 của Mi thấp hơn nhiều so với Do (bảng 3.1) nên sau khi phối hợp với $\mathrm{Co} \leq 2 \mathrm{mg} / \mathrm{L}$ cũng chuyển $\mathrm{R}$ sang $\mathrm{S}$, I của Mi cao hơn so với Do. Do đó trên lâm sàng phối hợp kháng sinh nên dựa vào MIC của kháng sinh phối hợp để mang lại hiệu quả cao, gia tăng diệt khuẩn, hạn chế kháng thuốc.

\section{KẾT LUÂN}

Sự phối hợp colistin với minocycline và colistin với doxycycline cho thấy làm gia tăng hiệu quả in vitro cho nhau với tỷ lệ cao trên chủng MDR A. baumannii. Với tình trạng MDR $A$. baumannii ngày càng gia tăng như hiện nay, sự phối hợp kháng sinh này giúp tối ưu hóa liều lượng colistin giảm tác dụng phụ trên bệnh nhân. Đồng thời phối hợp này còn giúp giảm MIC của kháng sinh phối hợp với colistin giúp gia tăng khả năng diệt khuẩn, hạn chế tình trạng kháng thuốc.

\section{TÀI LIẸU THAM KHẢO}

1. Hà ĐTT. Phân tích tình hình sử dung kháng sinh trong điều trị nhiểm khuẩn Gram âm đa kháng tai Bệnh viện đa khoa Đông Nai. Tạp chí y học Việt Nam. 2021;501(2):179.

2. Lima WG, Brito JCM, et al. Rate of polymyxin resistance among Acinetobacter baumannii recovered from hospitalized patients: a systematic review and meta-analysis. European journal of clinical microbiology \& infectious diseases : official publication of the European Society of Clinical Microbiology. 2020;39(8):1427-38.

3. Miyasaki $\mathbf{Y}$, Morgan MA, et al. In vitro activity of antibiotic combinations against multidrug-resistant strains of Acinetobacter baumannii and the effects of their antibiotic resistance determinants. FEMS Microbiol Lett. 2012;328(1):26-31.

4. Nation RL, Li J. Colistin in the 21st century. Current opinion in infectious diseases. 2009;22(6):535.

5. White RL, Burgess DS, et al. Comparison of three different in vitro methods of detecting synergy: time-kill, checkerboard, and E-test. Antimicrobial agents and chemotherapy. 1996;40(8):1914-8.

6. Yang YS, Lee $Y$, et al. In Vivo and In Vitro Efficacy of Minocycline-Based Combination Therapy for Minocycline-Resistant Acinetobacter baumannii. Antimicrobial agents and chemotherapy. 2016;60(7):4047-54.

7. CLSI. Performance Standards for Antimicrobial Susceptibility Testing. Clinical and Laboratory Standards Institute. 2021;CLSI supplement M100(31st ed).

\section{ĐÁNH GIÁ KẾT QUẢ AFATINIB ĐÎ̀̂U TRI UNG THƯ PHỔI KHÔNG TẾ BÀO NHỎ GIAI ĐOẠN IIIB-IV Có ĐộT BIỀN EGFR}

\section{TÓM TẮT}

Mục tiêu: Đánh giá kết quả điều trị ung thư phổi không tế bào nhỏ giai đoan IIIB-IV bằng Afatinib tại Bệnh viện Bạch Mai. Đối tượng và phương pháp nghiên cứu: 59 bệnh nhân ung thư phổi không tế bào nhỏ có đột biến EGFR giai đoạn tiến xa và di căn được điều trị bằng thuốc Afatinib tại Trung tâm $Y$ học hạt nhân và Ung bướu, bệnh viện Bạch Mai từ tháng

${ }^{1}$ Trung tâm Y học hạt nhân và Ung bướu, Bệnh viện Bach Mai

Chịu trách nhiệm chính: Võ Thị Huyền Trang

Email: bsubvohuyentrang@gmail.com

Ngày nhân bài: 9.8.2021

Ngày phản biên khoa hoc: 4.10 .2021

Ngày duyệt bài: 14.10.2021

\section{Võ Thị Huyền Trang1, Phạm Cẩm Phương ${ }^{1}$} 1/2019 đến tháng 4/2021. Kết quả nghiên cứu: $76,2 \%$ bênh nhân đat đáp ứng toàn bô, $13,6 \%$ bênh nhân ổn định bệnh; tỷ lệ kiểm soát bệnh đạt $89,8 \%$. Tỷ lệ đáp ứng từng loại tổn thương như sau: $U$ phổi nguyên phát $(68,5 \%)$; di căn phổi đối bên $(65,3 \%)$; di căn thân kinh trung ương $(80 \%)$; di căn thượng thận $(66,7 \%)$; di căn gan $(71,4 \%)$. Tỳ lệ đáp ứng ở nhóm bệnh nhân có đột biến gen EGFR thường gặp đạt $70,3 \%$ và ở nhóm hiếm gặp đạt $66,7 \%$. Tác dụng không mong muốn thường gặp nhất là tiêu chảy $(88,9 \%)$ và ban mụn trên da $(87,1 \%)$ chủ yếu ở độ 1 và độ 2 . Không có bệnh nhân nào tử vong do tác dụng phụ không mong muốn. Kết luận: Bệnh nhân ung thư phổi không tế bào nhỏ giai đợoạn IIIIB-IV có đột biến gen EGFR điều trị bằng Afatinib cho tỷ lệ đáp ứng cao, dung nạp tốt. 